\title{
THE SEQUENCE OF VESSEL LIGATION AFFECTS TUMOR RELEASE INTO THE CIRCULATION
}

Yuji Kurusu, MDa

Jun-ichi Yamashita, MD ${ }^{\mathrm{a}}$

Naoko Hayashi, MD ${ }^{\mathrm{a}}$

Seiji Mita, MD ${ }^{\mathrm{a}}$

Noboru Fujino, $\mathrm{MD}^{\mathrm{b}}$

Michio Ogawa, MD
Objective: Whether the sequence of pulmonary vein and artery ligation in pulmonary lobectomy for carcinoma affects intraoperative hematogenous cancer cell dissemination is not known. We examined whether vessel ligation sequence affects the presence of circulating cancer cells as reflected by carcinoembryonic antigen messenger ribonucleic acid. Methods: We assayed for the transcripts of carcinoembryonic antigen messenger ribonucleic acid by reverse-transcriptase polymerase chain reaction in peripheral blood taken before, during, and after operation from 30 patients with non-small-cell lung cancer who underwent a curative lobectomy and from six patients with limited-stage small-cell lung cancer who were treated initially with chemotherapy followed by lobectomy. Each patient was randomly assigned before the operation to have either pulmonary vein ligation or pulmonary artery ligation first. Blood taken from 10 patients with interstitial pulmonary fibrosis who underwent an open lung biopsy and $\mathbf{4 1}$ healthy subjects served as a control. Results: No control samples were positive for transcripts. Sixteen of the preoperative blood samples from the $\mathbf{3 0}$ patients with non-small-cell cancers were positive. Of these 16, eight samples remained positive even after lobectomy was performed; the remaining eight samples (four in each ligation group) became negative. Of the 14 initially negative samples (seven in each ligation group), nine samples became positive during the operation. Such conversion during the operation was more common with arterial ligation first (six patients, 85.7\%) than with venous ligation first (three patients, 42.9\%). Samples from all six patients with small-cell cancer were positive before the operation, and five of six samples remained positive after the operation. Conclusions: Many patients with non-small-cell lung cancer have systemic disease even when they were thought to have resectable tumors. Ligating the pulmonary vein before ligating the artery may lessen intraoperative hematogenous dissemination. Most small-cell lung cancers represent systemic disease even when considered resectable. (J Thorac Cardiovasc Surg 1998;116:107-13)
$A^{\mathrm{n}}$ $\mathrm{n}$ unresolved question important to surgeons is whether the manipulation of malignant tumors during an operation promotes the release of the

From the Department of Surgery II, Kumamoto University School of Medicine, ${ }^{\mathrm{a}}$ and the Department of Thoracic Surgery, Kumamoto Chuo Hospital, ${ }^{\text {b }}$ Kumamoto, Japan.

This work was supported in part by a Grant-in-Aid for Cancer Research from the Ministry of Education, Science and Culture of Japan.

Received for publication Dec. 3. 1997; revisions requested Jan. 12, 1998; revisions received Jan. 30, 1998; accepted for publication Feb. 17, 1998.

Address for reprints: Michio Ogawa, MD, Department of Surgery II, Kumamoto University School of Medicine, Honjo 1-1-1, Kumamoto 860, Japan.

Copyright (c) 1998 by Mosby, Inc.

$0022-5223 / 98 \$ 5.00+0 \quad \mathbf{1 2 / 1 / 8 9 8 0 9}$ tumor cells into the bloodstream, thereby increasing the incidence of distant metastases. Because of this concern, some thoracic surgeons insist that, in the cases of lobectomies for lung carcinoma, the pulmonary vein (PV) should be ligated before the ligation of the pulmonary artery (PA) because this procedure may prevent tumor cell dissemination into the bloodstream; conversely, the reverse order may enhance tumor cell dissemination during an operation and promote metastasis formation. However, it is still controversial whether the order of ligation of the PV and PA during a resection for lung carcinoma has any clinical significance.

There is some evidence from animal studies that indicates that intraoperative manipulation of a tumor can enhance metastasis formation ${ }^{1}$; however, whether this is true for human beings is unclear. 
Recently, developments in molecular technology have permitted the detection of circulating tumor cells in the peripheral blood. ${ }^{2,3}$ Several researchers have used carcinoembryonic antigen (CEA) as the target gene because CEA messenger ribonucleic acid (mRNA) can be detected in almost all epithelial cells, including cancer cells, but not in nonepithelial cells. ${ }^{4,5}$ If CEA mRNA is detected in blood samples, this implies the presence of ectopic epithelial cells.

In this study, we detected the presence of CEA mRNA in the peripheral blood of patients with non-small-cell lung cancer (NSCLC) and small-cell lung cancer (SCLC) during the operation by means of the reverse-transcriptase polymerase chain reaction (RT-PCR) assay. This RT-PCR amplification method for CEA mRNA is an efficient means of detecting circulating cancer cells in the peripheral blood. ${ }^{6}$ This study was designed to clarify whether surgical manipulation indeed promotes the dissemination of tumor cells during an operation for lung cancer. In addition, we examined whether the sequence of ligation of vessels (PV and PA) during lobectomy for lung cancer has any influence on tumor cell dissemination into the bloodstream.

\section{Patients and methods}

Patients. We studied 30 patients with NSCLC, 21 men and 9 women, aged 52 to 72 years (mean, 63 years), who underwent a curative lobectomy with mediastinal lymph node dissection (R2) at the Department of Surgery II, Kumamoto University Hospital, and at the Department of Thoracic Surgery, Kumamoto Chuo Hospital, during the 11-month period from December 1996 to October 1997. In addition, we studied six patients with limited-stage SCLC, all men, aged 60 to 76 years (mean, 67 years), who were treated initially with chemotherapy followed by an operation. Each patient with SCLC received two or three cycles of chemotherapy, consisting of doxorubicin (Adriamycin) $40 \mathrm{mg} / \mathrm{m}^{2}$ per day on days 1 and 7 , cisplatin 50 $\mathrm{mg} / \mathrm{m}^{2}$ per day on days 2 and 8 , and etoposide $100 \mathrm{mg} / \mathrm{m}^{2}$ per day on days 4 to 6 . After two or three cycles when a greater than $50 \%$ reduction in the tumor was achieved, the patients underwent a surgical resection (lobectomy) of the primary tumor for better control of the primary site. Although the patients with SCLC included in this study do not meet the criteria in which surgical resection is generally acknowledged to be appropriate in Western countries, this mode of surgery was still widespread in Japan, and we performed it at patient request. Informed consent was obtained from each patient, and the study was approved by the ethics committees of our institutes.

The postoperative pathologic TNM stage (pTNM) was determined according to the classification of the International Union Against Cancer. ${ }^{7}$ The histologic classification of the resected tumor specimens was based on the
World Health Organization Histologic Typing of Lung Tumors. $^{8}$ When SCLC was suspected, immunostaining with chromogranin A was performed to confirm the diagnosis. To rule out potential mesotheliomas, hyaluronidase digestion followed by alcian blue staining was performed.

Blood samples. All procedures were performed after the patient had been given a general anesthetic and with the use of single-lung ventilation through a double-lumen endotracheal tube (Broncho-Cath; Mallinckrodt Medical Inc., St. Louis, Mo.). Patients were placed in the lateral decubitus position with arms extended on an arm rest. The operations performed for the 30 patients with NSCLC were a right upper lobectomy in six patients, a right middle lobectomy in one patient, right lower lobectomy in four patients, left upper lobectomy in 15 patients, and left lower lobectomy in four patients. The operations performed for the six patients with SCLC were a right upper lobectomy in two patients and a left upper lobectomy in four patients. All patients were randomly assigned before the operation to one of two surgical procedure groups according to the order of vessel ligation, PV-first group (PV ligation preceded the PA ligation) and PA-first group (PA ligation preceded the PV ligation). All the surgical procedures were uniformly and successfully performed by the two same authors (J.Y. and N.F.). Pulmonary vessel mobilization and ligation were the first manuevers after entry into the pleural space. Mediastinal lymph node dissection was performed after the completion of lobectomy. All the patients had uneventful postoperative recoveries.

During the operation, a polyethylene catheter (Becton Dickinson, Sandy, Utah) was inserted into the radial artery of the contralateral arm (opposite the lobectomy side) for monitoring the heart rate and blood pressure. Blood samples were taken from this line just before the operation, 5 minutes after the ligation of the PV in the PV-first group (or the PA in the PA-first group), followed by sampling 5 minutes after the ligation of the PA in the PV-first group (or the PV in the PA-first group), and finally 5 minutes after the completion of the lobectomy. These four sampling points in each patient were defined as points I, II, III, and IV, respectively.

As a control, blood samples were taken from the radial artery before the operation and again 5 minutes after the lung resection in 10 patients with interstitial pulmonary fibrosis who underwent an open lung biopsy for the histologic diagnosis. The diagnoses were usual interstitial pneumonia in seven patients and bronchiolitis obliterans organizing pneumonia in three patients. In addition, blood samples were obtained from the antecubital vein of 32 healthy volunteers, 23 men and 9 women aged between 24 and 65 years (mean, 50 years), and from the radial artery of 9 healthy volunteers, 7 men and 2 women aged between 24 and 42 years (mean, 31 years).

RNA extraction. A tube containing a $5 \mathrm{ml}$ blood sample, $10 \mathrm{ml}$ of $3 \%$ dextran, and $0.9 \%$ sodium chloride solution was shaken gently by hand and incubated for 20 minutes at room temperature. The supernatant was centrifuged at $3000 \mathrm{rpm}$, and the nucleated cells were recovered. After being washed with phosphate-buffered saline solution, the cells were pelleted and then lysed in Trizol 
Table I. CEA mRNA expression during operation for NSCLC in terms of the operative procedure

\begin{tabular}{|c|c|c|c|c|c|c|c|c|c|}
\hline \multirow{2}{*}{$\begin{array}{c}\text { Patient no./age } \\
(y r) / \text { sex }\end{array}$} & \multirow{2}{*}{$\begin{array}{c}\text { Histologic } \\
\text { type }\end{array}$} & \multirow{2}{*}{$\begin{array}{l}\text { Operation } \\
\text { performed }\end{array}$} & \multicolumn{3}{|c|}{ pTNM classification } & \multicolumn{4}{|c|}{$R T$-PCR for CEA mRNA point } \\
\hline & & & $T$ & $N$ & Stage & $I$ & II & III & $I V$ \\
\hline \multicolumn{10}{|l|}{ PV-first group* } \\
\hline $1 / 59 / \mathrm{M}$ & Adeno & LUL & 1 & 0 & I & + & + & + & + \\
\hline $2 / 55 / \mathrm{M}$ & Adeno & RLL & 2 & 0 & I & + & + & + & + \\
\hline $3 / 72 / \mathrm{M}$ & Squamous & LUL & 2 & 2 & IIIA & + & + & + & + \\
\hline $4 / 67 / \mathrm{F}$ & Adeno & RUL & 2 & 2 & IIIA & + & + & + & + \\
\hline $5 / 59 / \mathrm{M}$ & Squamous & LUL & 1 & 0 & I & + & - & - & - \\
\hline $6 / 63 / \mathrm{F}$ & Adeno & RUL & 2 & 0 & I & + & - & - & - \\
\hline $7 / 62 / \mathrm{M}$ & Large & RUL & 2 & 2 & IIIA & + & - & - & - \\
\hline 8/70/M & Adeno & LUL & 1 & 0 & I & + & - & - & - \\
\hline 9/61/M & Adeno & LLL & 2 & 0 & I & - & + & + & - \\
\hline $10 / 65 / \mathrm{M}$ & Squamous & LUL & 1 & 0 & I & - & + & + & - \\
\hline $11 / 54 / \mathrm{F}$ & Squamous & RUL & 2 & 0 & I & - & + & + & - \\
\hline $12 / 64 / \mathrm{M}$ & Adeno & LUL & 1 & 0 & I & - & - & - & - \\
\hline 13/69/M & Adeno & RLL & 2 & 0 & I & - & - & - & - \\
\hline $14 / 69 / F$ & Squamous & LUL & 2 & 0 & I & - & - & - & - \\
\hline $15 / 58 / \mathrm{M}$ & Adeno & LLL & 2 & 0 & I & - & - & - & - \\
\hline \multicolumn{10}{|l|}{ PA-first group $\dagger$} \\
\hline $16 / 63 / \mathrm{M}$ & Adeno & RML & 2 & 0 & I & + & + & + & + \\
\hline $17 / 67 / \mathrm{M}$ & Adeno & LLL & 2 & 2 & IIIA & + & + & + & + \\
\hline $18 / 68 / \mathrm{F}$ & Adeno & LUL & 2 & 0 & I & + & + & + & + \\
\hline 19/71/M & Squamous & RUL & 1 & 0 & I & + & + & + & + \\
\hline $20 / 64 / F$ & Large & LUL & 2 & 2 & IIIA & + & + & - & - \\
\hline $21 / 52 / \mathrm{M}$ & Adeno & LUL & 1 & 0 & I & + & + & - & - \\
\hline $22 / 56 / \mathrm{M}$ & Squamous & RLL & 2 & 0 & I & + & + & - & - \\
\hline 23/60/M & Squamous & LUL & 2 & 0 & I & + & + & - & - \\
\hline $24 / 70 / \mathrm{F}$ & Adeno & RLL & 1 & 0 & I & - & + & + & - \\
\hline $25 / 63 / \mathrm{M}$ & Adeno & LUL & 1 & 0 & I & - & + & + & - \\
\hline $26 / 59 / \mathrm{F}$ & Adeno & LUL & 2 & 0 & I & - & + & + & - \\
\hline $27 / 72 / \mathrm{M}$ & Adeno & LLL & 1 & 0 & I & - & + & + & - \\
\hline $28 / 62 / \mathrm{M}$ & Adeno & RUL & 2 & 0 & I & - & + & + & - \\
\hline $29 / 68 / \mathrm{M}$ & Adeno & LUL & 2 & 0 & I & - & + & + & - \\
\hline $30 / 53 / \mathrm{F}$ & Squamous & LUL & 2 & 0 & I & - & - & - & - \\
\hline
\end{tabular}

Plus signs (+) indicate positive results by RT-PCR for CEA mRNA. Minus signs $(-)$ indicate negative results by RT-PCR for CEA mRNA. Points I, II, III, and IV represent four blood sampling points for each patient. $p T N M$, Pathologic TNM; Adeno, adenocarcinoma; $L U L$, left upper lobectomy; $R L L$, right lower lobectomy; Squamous, squamous cell carcinoma; $R U L$, right upper lobectomy; Large, large-cell carcinoma; $L L L$, left lower lobectomy; $R M L$, right middle lobectomy.

* Patients whose PV was ligated first followed by PA ligation.

$\dagger$ Patients whose PA was ligated first followed by PV ligation.

reagent (GIBCO BRL, Eggenstein, Germany). Total RNA was extracted from the cell pellet by the acid guanidium thiocyanate-phenol-chloroform extraction procedure. ${ }^{9}$ After preparation, RNA was resuspended in $10 \mu \mathrm{l}$ diethylpyrocarbonate-treated water and stored at $-80^{\circ} \mathrm{C}$.

RT-PCR for CEA mRNA. The complementary deoxyribonucleic acid (cDNA) was synthesized from $2.0 \mu \mathrm{g}$ of total RNA in a total volume of $20 \mu \mathrm{l}$ containing $2 \mu \mathrm{l}$ of $10 \times$ PCR buffer, $2 \mu \mathrm{l}$ of $25 \mathrm{~mol} / \mathrm{L} \mathrm{MgCl}{ }_{2}, 10 \mathrm{nmol} / \mathrm{L}$ of deoxyribonucleoside trisphosphate mix, $2 \mu \mathrm{l}$ of $0.1 \mathrm{~mol} / \mathrm{L}$ dithiothreitol, $0.5 \mu \mathrm{g}$ of oligo primer, and 200 units of SuperScriptII RT (all reagents were obtained from GIBCO BRL). The reaction mix was incubated for 50 minutes at $42^{\circ} \mathrm{C}, 15$ minutes at $70^{\circ} \mathrm{C}$, and chilled on ice. To inactivate the reverse transcriptase, 200 units of Escherichia coli $\mathrm{RNaseH}$ (GIBCO BRL) was incubated for 60 minutes at $37^{\circ} \mathrm{C}$.
To monitor cDNA synthesis, $2 \mu \mathrm{l}$ of the mixture was subjected to a RT-PCR for $\beta$-actin. Twenty-five $\mu$ l of the PCR reaction mix contained $2 \mu \mathrm{l}$ of cDNA from the previous RT reaction, $2.5 \mu \mathrm{l}$ of $10 \times \mathrm{PCR}$ buffer, 1.17 $\mu \mathrm{mol} \mathrm{MgCl}_{2}, 2.5 \mu \mathrm{l}$ of dimethylsulfoxide, $37.5 \mathrm{nmol} / \mathrm{L}$ deoxyribonucleoside trisphosphate mix, $25 \mathrm{pmol} / \mathrm{L}$ of sense and anti-sense primer (each), and 0.5 units of Taq DNA polymerase (GIBCO BRL). Amplification was carried out in a thermocycler (Thermoblock Uno; Biometra, Goettingen, Germany) with an initial denaturation step of $95^{\circ} \mathrm{C}$ for 5 minutes followed by 35 cycles of denaturation at $95^{\circ} \mathrm{C}$ for 30 seconds annealing at $55^{\circ} \mathrm{C}$ for 1 minute and extension at $72^{\circ} \mathrm{C}$ for 1 minute. The reaction was terminated by a final extension step at $72^{\circ} \mathrm{C}$ for 5 minutes. The RT-PCR product migrated as a 1100 base-pair (bp) fragment in a $2 \%$ agarose gel electrophoresis. The $\beta$-actin primer sequences were as follows: 5'-ATGGATGAT- 


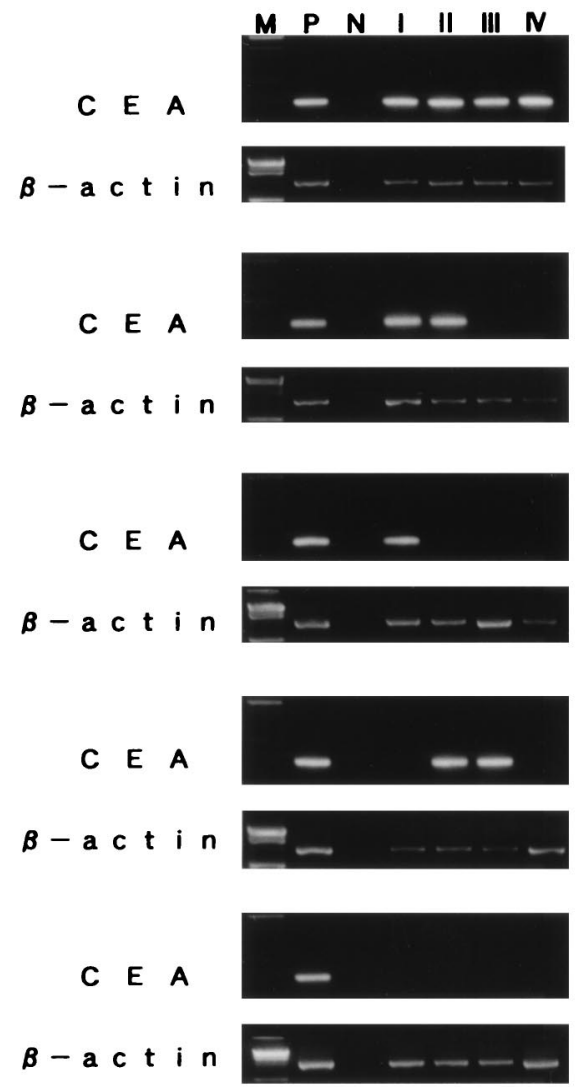

Fig. 1. Five patterns of CEA mRNA expression by RTPCR in blood samples sequentially obtained during operations for patients with NSCLC. Points I, II, III, and IV represent the four blood sampling points in each patient as described in the Patients and methods section. Lanes $M$, $P$, and $N$ contain the molecular weight marker, positive control, and negative control, respectively. Lanes $I$ through $I V$ contain the four sampling points as described.

\section{GATATCGCCGCG-3' and 5'-CTAGAAGCATTTGC- GGTGGACGATGGAGGGGCC-3'.}

The first PCR amplification was performed with primers CEA-A and CEA-B, followed by a second PCR amplification with primers CEA-C and CEA-B. The CEA primer sequences were: CEA-A, 5' -TCTGGAACTTCTCCTGGTCTCTCAGCTGG-3'; CEA-B, 5' -TGTAGCTGTTGCAAATGCTTTAAGGAAGAAGC-3'; and CEA-C, 5'-GGGCCACTGTCGGCATCATGATTGG-3' 5, 10 For the first PCR amplification, $1 \mu \mathrm{l}$ of the cDNA synthesis mix was used in a final volume of $25 \mu \mathrm{l}$. The reaction mix contained all the components as stated for the $\beta$-actin PCR except that the $\beta$-actin primers that were replaced by CEA-A and CEA-B (25 pmol/L each). The amplification conditions included denaturation at $95^{\circ} \mathrm{C}$ for 30 seconds, annealing at $63^{\circ} \mathrm{C}$ for 1 minute, and extension at $72^{\circ} \mathrm{C}$ for 1 minute for 30 cycles by a final extension step at $72^{\circ} \mathrm{C}$ for 5 minutes. The second nested PCR amplification was performed in the same way using $2 \mu$ l of the first PCR

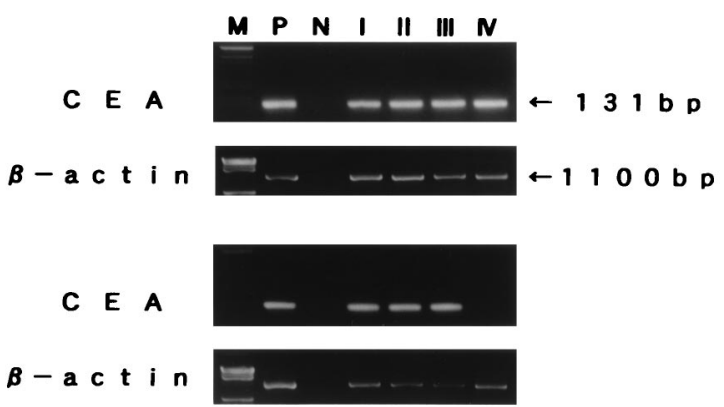

Fig. 2. Two patterns of CEA mRNA expression by RTPCR in blood samples sequentially obtained during the operations for patients with SCLC. Points I, II, III, and IV represent the four blood sampling points in each patient as described in the Patients and methods section. Lanes $M$, $P$, and $N$ contain the molecular weight marker, positive control, and negative control, respectively. Lanes $I$ through $I V$ contain the four sampling points as described.

reaction mix and the primers CEA-C and CEA-B. The amplification conditions were: denaturation at $95^{\circ} \mathrm{C}$ for 30 seconds, annealing at $60^{\circ} \mathrm{C}$ for 1 minute, and extension at $72^{\circ} \mathrm{C}$ for 1 minute for 30 cycles. The external (first) CEA RT-PCR resulted in a 160-bp fragment, and the internal (second) PCR amplification yielded a 131-bp product.

As a positive control, we used $2.0 \mathrm{ng}$ of total RNA from a NSCLC line EBC-1 (Japanese Research Resources Bank, Tokyo, Japan). The absence of contamination was routinely checked by RT-PCR amplification of control negative samples, in which the RNA was replaced with sterile water. All RT-PCR products were separated by electrophoresis in a 3\% agarose gel in Tris-borate-ethylene diamine tetraacetic acid (TBE) buffer and visualized by ethidium bromide staining. The molecular weights were determined with a DNA molecular weight marker (Boehringer Mannheim, Mannheim, Germany).

\section{Results}

CEA mRNA expression in blood in NSCLC. None of the preoperative and intraoperative blood samples obtained from 10 patients with interstitial pulmonary fibrosis and none of the 41 control peripheral blood samples obtained from healthy volunteers were positive for CEA mRNA by RTPCR. Table I shows the results of RT-PCR for CEA mRNA and the clinical characteristics of all the patients with NSCLC included in this study. Immunohistochemical staining for CEA revealed that intense CEA staining was uniformly observed in tumor cells in all 30 NSCLC specimens (data not shown). There were five patterns of CEA mRNA expression by RT-PCR in the blood samples sequentially obtained during the operation in the $30 \mathrm{pa}-$ tients with NSCLC at sampling points I, II, III, and 
IV. A representative case of each pattern of CEA mRNA expression by RT-PCR is shown in Fig. 1.

No significant association was found between CEA mRNA expression by RT-PCR and age, sex, histologic type, and operation performed. When CEA mRNA expression by RT-PCR was compared with respect to TNM stage, the preoperative blood samples (point I) of all five patients with stage IIIA NSCLC were positive: three patient samples were $(+)(+)(+)(+)$, one patient's samples were $(+)(+)(-)(-)$, and one patient's status was $(+)(-)$ $(-)(-)$ at sampling points I, II, III and IV, respectively.

The CEA mRNA expression in the peripheral blood samples during surgery for the 30 patients with NSCLC in terms of the operative procedure is summarized in Table II. The preoperative blood samples from 16 of 30 patients were positive (point I). Of these 16 patients, the samples from eight patients (four patients each in the PV-first group and the PA-first group) were positive for CEA mRNA at all sampling points, even after the completion of lobectomy, that is $(+)(+)(+)(+)$. In addition, peripheral blood samples obtained 1 to 2 days after the operations were positive in these eight patients (data not shown). The most striking difference in CEA mRNA expression between the PVfirst group and the PA-first group is that there were four patients in the PV-first group whose samples were $(+)(-)(-)(-)$ at the four sampling points, respectively, whereas none of the patients in the PA-first group had this pattern. In addition, there were four patients in the PA-first group but none in the PV-first group whose pattern of CEA mRNA expression was $(+)(+)(-)(-)$ at the four sampling points. Furthermore, there was a higher incidence of patients with a pattern of $(-)(+)(+)(-)$ in the PA-first group $(66.7 \%)$ than in the PV-first group $(33.3 \%)$, and there was a higher incidence of patients whose samples were consistently negative, $(-)(-)(-)(-)$, in the PV-first group $(80.0 \%)$ than in the PA-first group (20.0\%).

CEA mRNA expression in blood in SCLC. Fig. 2 and Table III show the results of the RT-PCR amplification for CEA mRNA and the clinical characteristics of the six patients with SCLC included in this study. The preoperative blood samples from these patients were positive. Of these six patients with SCLC, five had samples that were consistently positive throughout the sampling period, even after the removal of the tumor, that is, $(+)(+)(+)(+)$. Only one patient with SCLC had a sample negative
Table II. Summary of CEA $m R N A$ expression during operation for NSCLC

\begin{tabular}{|c|c|c|c|c|c|c|}
\hline \multicolumn{4}{|c|}{$\begin{array}{c}R T-P C R \text { for } \\
C E A m R N A \\
\text { point }\end{array}$} & \multirow{2}{*}{$\begin{array}{l}\text { No. of patients } \\
\text { in PV-first } \\
\text { group (\%) }\end{array}$} & \multirow{2}{*}{$\begin{array}{l}\text { No. of patients } \\
\text { in } P A-\text {-first } \\
\text { group }(\%)\end{array}$} & \multirow{2}{*}{$\begin{array}{c}\text { Total } \\
(\%)\end{array}$} \\
\hline$I$ & $I I$ & III & $I V$ & & & \\
\hline+ & + & + & + & $4(50.0)$ & $4(50.0)$ & $8(100)$ \\
\hline+ & + & - & - & $0(0.0)$ & $4(100.0)$ & $4(100)$ \\
\hline+ & - & - & - & $4(100.0)$ & $0(0.0)$ & $4(100)$ \\
\hline- & + & + & - & $3(33.3)$ & $6(66.7)$ & $9(100)$ \\
\hline- & - & - & - & $4(80.0)$ & $1(20.0)$ & $5(100)$ \\
\hline \multicolumn{4}{|c|}{ Total } & 15 & 15 & 30 \\
\hline
\end{tabular}

for CEA mRNA by RT-PCR after the completion of the lobectomy, that is, $(+)(+)(+)(-)$.

\section{Discussion}

A method to detect small numbers of tumor cells in the blood may permit the evaluation of their role in the disease process. Morphologic techniques, flow cytometry, conventional cytogenetics, and immunocytochemistry have been used to detect circulating tumor cells. ${ }^{2}$ However, these techniques are relatively insensitive and dependent on the availability of antibodies to tumor-associated cell-surface antigens, which may yield false-positive results if the antibodies cross-react with normal antigens or tumor antigens are presented on host immune cells. ${ }^{2,11}$ The advent of the PCR has permitted the detection of one malignant cell up to $10^{7}$ normal cells by amplification of tumor-specific sequences. ${ }^{2,3,12}$ Recently, Gerhard and associates ${ }^{5}$ developed a sensitive RT-PCR assay for the specific detection of CEA-expressing tumor cells in the bone marrow, and Mori and associates ${ }^{6}$ have demonstrated that RT-PCR amplification of CEA mRNA is an efficient means of detecting circulating cancer cells in the peripheral blood.

The detachment of cancer cells from the primary tumor is one of the early sequential events in the metastatic cascade. Therefore surgeons always worry that the manual manipulation of a tumor during an operation might enhance the shedding of cancer cells into the bloodstream, resulting in an increase in the incidence of distant metastases. One surgical technique that might prevent such shedding is to ligate the efferent vessels first. In lung carcinoma operations, ligating the PV before ligating the PA has been postulated as a way to prevent tumor cell dissemination into the bloodstream. Although 
Table III. CEA $m R N A$ expression during operation for SCLC in terms of the operative procedure

\begin{tabular}{|c|c|c|c|c|c|c|c|c|c|}
\hline \multirow{2}{*}{$\begin{array}{c}\text { Patient no/ } \\
\text { age (yr) }\end{array}$} & \multirow{2}{*}{$\begin{array}{c}\text { Histologic } \\
\text { type }\end{array}$} & \multirow{2}{*}{$\begin{array}{l}\text { Operation } \\
\text { performed }\end{array}$} & \multicolumn{3}{|c|}{ pTNM classification } & \multicolumn{4}{|c|}{ RT-PCR for CEA $m R N A$ point } \\
\hline & & & $T$ & $N$ & Stage & $I$ & $I I$ & III & $I V$ \\
\hline \multicolumn{10}{|c|}{ PV-first group* } \\
\hline $31 / 60$ & SCLC & LUL & 2 & 0 & I & + & + & + & + \\
\hline $32 / 67$ & SCLC & RUL & 2 & 2 & IIIA & + & + & + & + \\
\hline $33 / 76$ & SCLC & LUL & 1 & 0 & I & + & + & + & - \\
\hline \multicolumn{10}{|l|}{ PA-first group $\dagger$} \\
\hline $34 / 62$ & SCLC & RUL & 1 & 0 & I & + & + & + & + \\
\hline $35 / 65$ & SCLC & LUL & 2 & 0 & I & + & + & + & + \\
\hline $36 / 69$ & SCLC & LUL & 3 & 0 & IIIA & + & + & + & + \\
\hline
\end{tabular}

All patients were men. Plus signs (+) indicate positive results by RT-PCR for CEA mRNA. Minus signs (-) indicate negative results by RT-PCR for CEA mRNA. Points I, II, III, and IV represent four blood sampling points for each patient. $p T N M$, Pathologic TNM; LUL, left upper lobectomy; RUL, right upper lobectomy.

* Patients whose PV was ligated first followed by PA ligation.

$\dagger$ Patients whose PA was ligated first followed by PV ligation.

there has been considerable debate over this recommendation, it has not been rigorously tested.

In the present study, to examine whether the order of vessel ligation during an operation for lung carcinoma has any influence on the presence of tumor cells in the circulation, we assayed by RTPCR for the presence of CEA mRNA in the peripheral blood of patients undergoing operations for lung carcinoma. Surprisingly, CEA mRNA was detected in the peripheral blood samples obtained before the operation in 16 of 30 patients $(53.3 \%)$ with resectable NSCLC. Another unexpected finding in this study was the high incidence ( 8 of 30 patients, 26.7\%) of positive CEA mRNA in the peripheral blood throughout the study period, even after the completion of the lobectomy, that is, $(+)(+)(+)(+)$, at all four time points. Although the technique does not allow for specific identification of tumor cells and positive finding of CEA mRNA merely indicates the presence of epithelial cells, our results suggest that a considerable proportion of patients who appear to have resectable NSCLC might be better regarded as having systemic disease. In this study, we performed single-point blood sampling for patients before operation. However, cancer cells may be intermittently shedding into the bloodstream. ${ }^{13}$

Thus sampling errors may have occurred in that patients who had negative blood samples when the initial blood was drawn might have circulating tumor cells intermittently at another time or under other circumstances.

With respect to the order of vessel ligation during surgery for NSCLC, our results seem to support the opinion that the PV should be ligated first, before the ligation of the PA. Both in the
PV-first group and the PA-first group, the blood samples from eight patients in each group were positive for CEA mRNA before surgery. Subsequently, the samples from four patients in each group turned negative just after the ligation of the $\mathrm{PV}$, that is, $(+)(-)(-)(-)$ in the PV-first group and $(+)(+)(-)(-)$ in the PA-first group. These results suggest that the ligation of the PV may partly prevent the shedding of cancer cells into the bloodstream. Furthermore, in the PV-first group, blood samples from three of seven patients (42.9\%) that were negative for CEA mRNA before surgery turned positive during surgery, that is, $(-)(+)(+)(-)$. The incidence of this change was higher in the PA-first group (six of seven patients, $85.7 \%$ ) than in the PV-first group.

The relationship between circulating tumor cells and the development of metastatic disease is not fully understood, and the presence of tumor cells in the blood does not necessarily indicate the subsequent risk of clinical systemic disease. It is generally believed that very few of tumor cells that shed into the bloodstream succeed in establishing secondary tumors. ${ }^{14}$ Thus patients who have persistently positive blood samples after lobectomy may be those at risk for systemic relapse. However, our findings should alert surgeons to the possible danger of tumor cell dissemination during an operation and suggest that the PV should be ligated first, before the ligation of the PA, in patients undergoing a lobectomy for NSCLC. Future follow-up studies in a larger cohort of patients with NSCLC should be done to examine whether the patients with positive CEA mRNA might have more metastases, shorter survivals, or shorter disease-free intervals than those who did not have positive results. 
Our study also demonstrated that most patients with SCLC had blood samples that were positive by RT-PCR for CEA mRNA before the operation despite initial chemotherapy; samples remained positive even after removal of the primary tumor, that is, $(+)(+)(+)(+)$. These results suggest that patients with SCLC, even if they have limited-stage disease, are likely to have systemic disease, and that a local treatment modality, such as surgical resection, is likely to have little impact on their prognosis.

In conclusion, the molecular detection of CEA mRNA in the peripheral blood of patients with lung carcinoma suggests that (1) many patients with resectable NSCLC are likely to have systemic disease; (2) surgical manipulation can promote the release of tumor cells into the bloodstream, but the ligation of the PV before the ligation of the PA may partly prevent such release during surgery; and (3) most patients with SCLC are likely to have systemic disease.

\section{REFERENCES}

1. Nishizaki T, Matsumata T, Kanematsu T, Yasunaga C, Sugimachi K. Surgical manipulation of VX2 carcinoma in the rabbit liver evokes enhancement of metastases. J Surg Res 1990;49:92-7.

2. Johnson P, Burchill S, Selby P. The molecular detection of circulating tumour cells. Br J Cancer 1995;72:268-76.

3. Smith B, Selby P, Southgate J, Pittman K, Bradley C, Blair GE. Detection of melanoma cells in peripheral blood by means of reverse transcriptase and polymerase chain reaction. Lancet 1991;338:1227-9.

4. Mori M, Mimori K, Inoue H, Barnard GF, Tsuji K, Nanbara $\mathrm{S}$, et al. Detection of cancer micrometastases in lymph nodes by reverse transcriptase-polymerase chain reaction. Cancer Res 1995;55:3417-20.

5. Gerhard M, Juhl H, Kalthoff H, Schreiber HW, Wagener C, Neumaier M. Specific detection of carcinoembryonic antigen-expressing tumor cells in bone marrow aspirates by polymerase chain reaction. J Clin Oncol 1994;12:725-9.

6. Mori M, Mimori K, Ueo H, Karimine N, Barnard GF, Sugimachi K, et al. Molecular detection of circulating solid carcinoma cells in the peripheral blood: the concept of early systemic disease. Int J Cancer 1996;68:739-43.

7. International Union Against Cancer. TNM classification of malignant tumors. 4th ed. Geneva: International Union Against Cancer; 1987. p. 69-73.

8. The World Health Organization histologic typing of lung tumours. 2nd ed. Am J Clin Pathol 1982;77:123-36.

9. Chomczynski P, Sacchi N. Single-step method of RNA isolation by acid guanidium thiocyanate-phenol-chloroform extraction. Anal Biochem 1987;162:156-9.

10. Schrewe H, Thompson J, Bona M. Cloning of the complete gene for carcinoembryonic antigen: analysis of its promotor indicates a region conveying cell type-specific expression. Mol Cell Biol 1990;10:2738-48.

11. Heyderman E, McCartney JC. Epithelial membrane antigen and lymphoid cells [letter]. Lancet 1985;1:109.

12. Burchill SA, Bradbury MF, Smith B, Lewis IJ, Selby P. Neuroblastoma cell detection by reverse transcriptase polymerase chain reaction (rt-PCR) for tyrosine hydroxylase messenger RNA. Int J Cancer 1994;57:671-5.

13. Glaves D, Huben R, Weiss L. Haematogenous dissemination of cells from human renal adenocarcinoma. $\mathrm{Br} \mathrm{J}$ Cancer 1988;54:32-5.

14. Fidler I. The biology of human cancer metastasis. Acta Oncol 1991;30:669-75 